\title{
Impact Of Underlying Pulmonary Diseases On Treatment Outcomes In Early-Stage Non-Small Cell Lung Cancer Treated With Definitive Radiotherapy
}

Hakyoung Kim, ',* Hongseok Yoo, ${ }^{2, *}$ Hongryull Pyo, ${ }^{3}$ Yong Chan Ahn, ${ }^{3}$ Jae Myoung Noh, ${ }^{3}$ Sang Gyu Ju, ${ }^{4}$ Woojin Lee, ${ }^{4}$ Byoungsuk Park, ${ }^{4}$ Jin Man Kim, ${ }^{4}$ Noeul Kang, ${ }^{2}$ Sun Hye Shin, ${ }^{2}$ Man Pyo Chung, ${ }^{2}$ Sumin Shin, (D) ${ }^{5}$ Hye Seung Kim, (D) ${ }^{6}$ Minsu Park, (iD) ${ }^{6}$ Hye Yun Park (iD) ${ }^{2}$

'Department of Radiation Oncology, Korea University Guro Hospital, Korea University College of Medicine, Seoul, South Korea; ${ }^{2}$ Division of Pulmonary and Critical Care Medicine, Department of Medicine, Samsung Medical Center,

Sungkyunkwan University School of Medicine, Seoul, South Korea; ${ }^{3}$ Department of Radiation

Oncology, Samsung Medical Center, Sungkyunkwan University School of Medicine, Seoul, South Korea; ${ }^{4}$ Department of Radiation Oncology, Samsung Medical Center, Seoul, South Korea; ${ }^{5}$ Department of Thoracic and Cardiovascular Surgery, Samsung Medical Center, Sungkyunkwan University School of Medicine, Seoul, South Korea; ${ }^{6}$ Statistics and Data Center, Samsung Biomedical Research Institute, Samsung Medical Center, Seoul, Republic of Korea

*These authors contributed equally to this work

Correspondence: Hye Yun Park

Division of Pulmonary and Critical Care

Medicine, Department of Medicine, Samsung Medical Center, Sungkyunkwan University

School of Medicine, 8I Irwon-ro, Gangnam-gu, Seoul 0635I, Republic of Korea

Tel +82-2-3410-3429

Fax +82-2-3410-3849

Email hyeyunpark@skku.edu

Hongryull Pyo

Department of Radiation Oncology, Samsung Medical Center, Sungkyunkwan University

School of Medicine, 8I Irwon-ro, Gangnam-gu, Seoul 0635I, Republic of Korea

Tel +82-2-3410-2438

Fax +82-2-3410-2619

Email hr.pyo@samsung.com
This article was published in the following Dove Press journal: International Journal of Chronic Obstructive Pulmonary Disease

Purpose: Current guidelines recommend definitive radiotherapy for patients with medically inoperable early-stage non-small cell lung cancer (NSCLC). However, the impact of underlying pulmonary diseases on survival in those patients remains unclear.

Methods: We retrospectively reviewed the medical records of 234 patients with stage I-II NSCLC treated with definitive radiotherapy alone at Samsung Medical Center between January 2010 and October 2017. We compared survival outcomes according to the presence of underlying pulmonary diseases, including chronic obstructive pulmonary disease (COPD), combined pulmonary fibrosis and emphysema (CPFE), and idiopathic pulmonary fibrosis (IPF). The control group in this study was stage I-II NSCLC patients who were non-COPD, non-CPFE, and non-IPF.

Results: The median follow-up duration was 17 (range, 1-92) months. The median survival times of the control, COPD, CPFE, and IPF groups were 32, 49, 17, and 12 months, respectively $(P<0.001)$. In a Cox proportional hazards analysis for factors associated with overall survival, patients with COPD showed a similar risk of death (adjusted hazard ratio [HR], 1.306; 95\% confidence interval [CI], 0.723-2.358; $P=0.376$ ) compared to that of the control group, while patients with CPFE (adjusted HR, 3.382; 95\% CI, 1.472-7.769; $P=0.004$ ) and IPF (adjusted HR, 4.061; 95\% CI, 1.963-8.403; $P<0.001$ ) showed an increased risk of death.

Conclusion: Definitive radiotherapy may be a tolerable treatment for early-stage NSCLC with COPD. However, poor survival in early-stage NSCLC patients with IPF or CPFE requires further study to identify and develop patient selection criteria as well as an optimal radiotherapy modality.

Keywords: non-small cell lung cancer, pulmonary disease, radiotherapy, survival

\section{Introduction}

Surgical resection is the treatment of choice for patients with early-stage non-small cell lung cancer (NSCLC). However, a considerable number of patients are not eligible for surgical resection due to various factors such as old age, poor performance status, impaired cardio-pulmonary function, and co-morbidities. ${ }^{1}$ In particular, chronic obstructive pulmonary disease (COPD) and idiopathic pulmonary fibrosis (IPF) are two pulmonary co-morbidities which are significantly associated with increased morbidity and mortality after surgical resection for early-stage 
NSCLC. ${ }^{2-4}$ Moreover, since these two diseases not only share smoking, the most important risk of lung cancer, but are also themselves risk factors for lung cancer, clinicians or surgeons often encounter NSCLC patients with COPD or IPF. When surgery is not feasible in these patients, definitive radiotherapy can be an alternative treatment option. ${ }^{5}$

COPD is a chronic inflammatory lung disease that causes airflow obstruction and it is the most frequent concomitant disease in early-stage NSCLC patient. ${ }^{6,7}$ In lung cancer patients with radiotherapy, there are conflicting data regarding the effect of COPD on the risk of radiation pneumonitis (RP) development. ${ }^{8-10}$ Some studies showed that the presence of COPD or emphysema is associated with a higher risk of $\mathrm{RP},{ }^{8,10}$ while a retrospective study reported that RP was relatively mild in patients with severe COPD. ${ }^{9}$ However, the impact of coexisting COPD on overall survival beyond RP after definitive radiotherapy has not been fully investigated.

IPF is a chronic progressive interstitial lung disease with a five-year survival rate of $20-40 \%{ }^{11}$ A significant reduction in the survival of IPF patients who develop lung cancer has been well documented. Treatment-related complications such as acute exacerbation or pneumonia following surgery or radiotherapy for NSCLC have led to difficulties in determining the optimal treatment strategies for those patients. ${ }^{12-15}$ Furthermore, several reports suggested that patients with combined pulmonary fibrosis and emphysema (CPFE), a recently described disease entity which contain features of both IPF and emphysema, are at a high risk of lung cancer development and are associated with a poor prognosis. ${ }^{16,17}$ However, the treatment outcomes of definitive radiotherapy on early-stage NSCLC patients with IPF or CPFE are not clear.

Thus, we aimed to evaluate the impact of the underlying chronic pulmonary diseases of COPD, CPFE and IPF on survival outcome following definitive radiotherapy in patients with medically inoperable stage I-II NSCLC.

\section{Methods}

\section{Patients}

We retrospectively identified 234 patients who received definitive radiotherapy alone for stage I or II NSCLC between January 2010 and October 2017 from the lung cancer radiotherapy registry of Samsung Medical Center, and who did not have previous or concurrent malignancy except for thyroid cancer. The Institutional Review Board approved this study (no. 2018-08-108) and informed consent was waived due to the retrospective nature. We declared that patients' data were confidential and this study was conducted according to the Declaration of Helsinki.

\section{Measurements And Definitions}

Spirometry and diffusing capacity of the lungs for carbon monoxide (DLco) were performed using a Vmax 22 system (SensorMedics, Yorba Linda, CA, USA) according to criteria established by the American Thoracic Society/European Respiratory Society. ${ }^{18,19}$ The absolute values of the forced vital capacity (FVC), forced expiratory volume in one second $\left(\mathrm{FEV}_{1}\right)$, and DLco were obtained and the percentage of the predicted values ( $\%$ pred) for $\mathrm{FEV}_{1}$ and $\mathrm{FVC}$ were calculated from equations obtained with a representative Korean sample. ${ }^{20}$ COPD was defined as pre-bronchodilator $\mathrm{FEV}_{1} / \mathrm{FVC}<0.70$ and its severity was graded as mild $\left(\mathrm{FEV}_{1} \geq 80 \%\right.$ predicted $)$, moderate $\left(50 \% \leq \mathrm{FEV}_{1}<80 \%\right.$ predicted), severe $\left(30 \% \leq \mathrm{FEV}_{1}<50 \%\right.$ predicted $)$, or very severe ( $\mathrm{FEV}_{1}<30 \%$ predicted). A low DLco was defined as DLco $<80 \%$ predicted. ${ }^{21}$ Never smoker was defined as a person having smoked less than 100 cigarettes in his or her life time.

With respect to the diagnosis of IPF, ${ }^{22}$ the presence of a typical radiological pattern, peripheral and basal predominant reticular opacities, and honeycombing with or without traction bronchiectasis were seen on high-resolution computed tomography (HRCT) scans. Moreover, CPFE was diagnosed if diffuse distribution of fibrosis with emphysema throughout the lungs was observed on HRCT along with abnormalities of gas exchange in the same patient. ${ }^{23}$ The diagnoses of IPF and CPFE were reviewed by two of the authors (H.Y. and H.Y.P). Patients with IPF or CPFE and COPD were classified as IPF or CPFE. In the current study, we defined the control group as non-COPD, nonCPFE, and non-IPF.

\section{Diagnostic And Staging Scheme}

All tumors were staged based on the seventh edition of the American Joint Committee on Cancer tumor staging criteria. ${ }^{24}$ All suspicious ipsilateral mediastinal nodal metastases were confirmed by histological and/or cytological examination (mediastinoscopy, endobronchial ultrasound-guided transbronchial needle aspiration [EBUS-TBNA], Chamberlain incision or thoracoscopy). 18F-fluorodeoxyglucose positron emission tomography (PET)/computed tomography (CT) was performed in all patients. 


\section{Treatment Scheme}

The gross tumor volumes (GTVs) were delineated under the lung window setting. The GTVs were delineated on the internal target volume concept following four-dimensional CT considering significant respiratory motion. The clinical target volumes (CTVs) were generated with $5 \mathrm{~mm}$ expansion of the GTVs in all directions, which were then modified according to the adjacent anatomic structures. The percentage lung volume that received $\geq 20$ Gy was to be kept $\leq 35 \%$, and the mean lung dose was $\leq 20 \mathrm{~Gy}$. The maximum doses to the spinal cord and esophagus were not to exceed 45 Gy and $60 \mathrm{~Gy}$, respectively. The prescription policy was to deliver at least $97 \%$ of the prescribed dose to $95 \%$ of the CTVs. Two different dose-fractionation schedules were used for the delivery of $60 \mathrm{~Gy}$ in either 20 fractions over 4 weeks or in 15 fractions over 3 weeks, respectively. The biologically equivalent doses at $\alpha / \beta$ of $10 \mathrm{~Gy}\left(\mathrm{BED}_{10}\right)$ were $78 \mathrm{~Gy}$ and 84 Gy, respectively. If the shortest distance between the CTV margin and the esophagus was $\geq 1.5 \mathrm{~cm}, 60 \mathrm{~Gy}$ in 15 fractions was preferred to $60 \mathrm{~Gy}$ in 20 fractions. Stereotactic body radiation therapy (SBRT) was conducted for NSCLC of small size $(\leq 4 \mathrm{~cm})$ and peripherally-located tumors. Two different dose-fractionation schedules were used for the delivery of $60 \mathrm{~Gy}$ in four fractions or $60-70 \mathrm{~Gy}$ in $8-10$ fractions, respectively. For treatment planning, the radiotherapy technique was selected individually based on estimated pulmonary complications. A total of 133 patients were treated with three-dimensional conformal radiotherapy (3DCRT, $56.8 \%$ ), 91 with SBRT (38.9\%), and 10 received intensitymodulated radiotherapy (IMRT, 4.3\%) as it was difficult to safely cover the whole disease extent while satisfying the dose-volume constraints using the 3DCRT technique.

\section{Surveillance}

Physical examination, blood tests, chest CT scan, and/or PETCT were carefully performed every 3 months for 2 years after radiotherapy and then every 6 months thereafter to detect disease progression during follow-up. Revised Response Evaluation Criteria in Solid Tumors (RECIST) guidelines (Version 1.1) were used to evaluate tumor response. Treatment-related pulmonary complications, excluding infection-related cases, were evaluated using the Common Terminology Criteria for Adverse Events version 4.0.

\section{Statistical Analysis}

Data are reported as numbers (percentages) for categorical variables and as median (interquartile range, IQR) for continuous variables. The baseline characteristics were compared among control, COPD, CPFE, and IPF patients using the Pearson's chi-square test or the Fisher's exact test for categorical variables and the Kruskal-Wallis test for continuous variables. The overall survival (OS) was defined as the time from the start date of the radiotherapy until the date of death from any cause or the latest documented follow-up. We calculated hazard ratios (HRs) with $95 \%$ confidence intervals (CIs) for all-cause mortality using Cox proportional hazards regression models. We adjusted for age (continuous), smoking status (never, or ever), performance status (ECOG $\leq 1$ or $\geq 2$ ), clinical stage (clinical stage I or II), $\mathrm{FEV}_{1} \%$ predicted $(\leq 80 \%$ or $>80 \%$ ) and DLco $\%$ predicted ( $\leq 60 \%,>60 \%$ or unknown) in model 1 to account for potential confounding factors at the time of NSCLC diagnosis. The model 2 was further adjusted for radiotherapy technique (SBRT or 3DCRT/IMRT). $P$-values $<0.05$ were considered statistically significant. Statistical analysis was performed using IBM SPSS Statistics for Windows, version 24.0 (IBM Corporation, Armonk, NY, USA), SAS, version 9.4 (SAS Institute, Cary, NC, USA), and R-packages, version 3.5.1 (Vienna, Austria; http://www.Rproject.org).

\section{Results \\ Baseline Characteristics}

The clinical characteristics of the study patients are summarized in Table 1 . The median age of the study population was 76 years (IQR, 72 to 80 years). The majority of patients were male $(80.8 \%)$. Most patients were either current or ex-smokers (79.1\%). Among 234 patients, 132 (56.4\%) were diagnosed with COPD, 16 (6.8\%) with CPFE, and 22 (9.4\%) with IPF. The control group included one patient with interstitial lung disease associated with vasculitis. Two out of 22 patients with IPF received pirfenidone. In the pulmonary function tests, impaired $\mathrm{FEV}_{1}$ $(\leq 50 \%)$ and DLCO $(\leq 60 \%)$ were seen in $20.5 \%(48 / 234)$ and $35.8 \%$ (73/204) of patients, respectively. Compared to the control group, patients with underlying pulmonary disease had significantly higher percentages of young age, males, smoking history, squamous cell carcinoma, and impaired $\mathrm{FEV}_{1}$ and DLco. There were no statistically significant differences in ECOG performance status, clinical stages, and radiotherapy technique among the four groups. In terms of planning dose-volume parameters for lung, the mean lung dose and the percentage volumes of lung receiving $\geq 5$ Gy and $\geq 20$ Gy were similar between the four groups. 
Table I Clinical Characteristics Of Patients Treated With Definitive Radiotherapy For Early Stage NSCLC (N = 234)

\begin{tabular}{|c|c|c|c|c|c|}
\hline Characteristics & Control* $(n=64)$ & COPD $(n=132)$ & CPFE $(n=16)$ & IPF $(n=22)$ & $P$ Value \\
\hline Age (years) & $78.5(74.0-81.5)$ & $75.0(71.0-79.0)$ & $76.0(74.0-79.0)$ & $74.5(72.0-79.0)$ & 0.036 \\
\hline $\begin{array}{l}\text { Sex } \\
\text { Female } \\
\text { Male }\end{array}$ & $\begin{array}{l}30(46.9 \%) \\
34(53.1 \%)\end{array}$ & $\begin{array}{l}\text { I5 (II.4\%) } \\
\text { II (88.6\%) }\end{array}$ & $\begin{array}{l}0(0 \%) \\
16(100 \%)\end{array}$ & $\begin{array}{l}0(0 \%) \\
22(100 \%)\end{array}$ & $<0.001$ \\
\hline $\begin{array}{l}\text { Smoking Status } \\
\text { Never smoker } \\
\text { Current or Ex-smoker } \\
\text { Pack-years }{ }^{\dagger}\end{array}$ & $\begin{array}{l}34(53.1 \%) \\
30(46.9 \%) \\
45(30-60)\end{array}$ & $\begin{array}{l}15(11.4 \%) \\
117(88.6 \%) \\
40(30-55)\end{array}$ & $\begin{array}{l}0(0 \%) \\
16(100 \%) \\
40(25-50)\end{array}$ & $\begin{array}{l}0(0 \%) \\
22(100 \%) \\
40(30-59)\end{array}$ & $<0.001$ \\
\hline $\begin{array}{l}\text { ECOG performance status } \\
0-1 \\
2-3\end{array}$ & $\begin{array}{l}45 \text { (70.3\%) } \\
19(29.7 \%)\end{array}$ & $\begin{array}{l}92(69.7 \%) \\
40(30.3 \%)\end{array}$ & $\begin{array}{l}9(56.3 \%) \\
7(43.7 \%)\end{array}$ & $\begin{array}{l}\text { I3 (59.1\%) } \\
9 \text { (40.9\%) }\end{array}$ & 0.542 \\
\hline $\begin{array}{l}\text { Clinical Stage } \\
\text { IA-IB } \\
\text { IIA-IIB }\end{array}$ & $\begin{array}{l}48(75.0 \%) \\
16(25.0 \%)\end{array}$ & $\begin{array}{l}96(72.7 \%) \\
36(27.3 \%)\end{array}$ & $\begin{array}{l}\text { II (68.8\%) } \\
5(31.2 \%)\end{array}$ & $\begin{array}{l}\text { I5 (68.2\%) } \\
7(31.8 \%)\end{array}$ & 0.914 \\
\hline $\begin{array}{l}\text { Histology } \\
\text { Adenocarcinoma } \\
\text { Squamous cell carcinoma } \\
\text { Others } \\
\text { Not proven }\end{array}$ & $\begin{array}{l}28(43.8 \%) \\
21(32.8 \%) \\
4(6.3 \%) \\
11(17.1 \%)\end{array}$ & $\begin{array}{l}31(23.5 \%) \\
75(56.8 \%) \\
7(5.3 \%) \\
19(14.4 \%)\end{array}$ & $\begin{array}{l}2(12.5 \%) \\
7(43.8 \%) \\
1(6.3 \%) \\
6(37.4 \%)\end{array}$ & $\begin{array}{l}5(22.7 \%) \\
10(45.5 \%) \\
1(4.5 \%) \\
6(27.3 \%)\end{array}$ & 0.02 \\
\hline 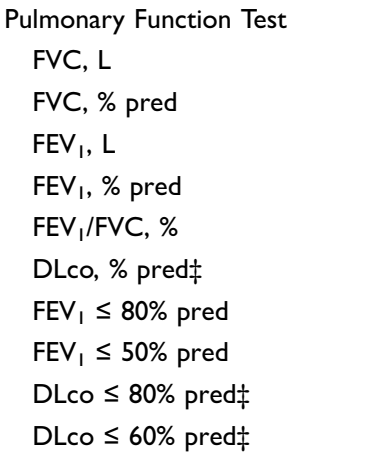 & $\begin{array}{l}2.6(2.1-3.0) \\
82.0(71.5-92.5) \\
2.0(1.6-2.4) \\
95.5(80.5-112.0) \\
77.0(74.0-81.5) \\
80.0(68.0-93.0) \\
16(25.0 \%) \\
1(1.6 \%) \\
27(50.9 \%) \\
7(13.2 \%)\end{array}$ & $\begin{array}{l}3.0(2.5-3.5) \\
80.5(67.5-90.5) \\
1.5(1.2-1.9) \\
64.0(46.0-75.5) \\
55.0(44.0-63.0) \\
67.0(54.5-87.0) \\
107(81.1 \%) \\
45(34.1 \%) \\
77(66.4 \%) \\
42(36.2 \%)\end{array}$ & $\begin{array}{l}3.4(3.1-3.8) \\
88.0(78.5-94.0) \\
2.2(2.0-2.5) \\
82.0(75.0-102.0) \\
63.0(60.0-73.5) \\
55.0(45.0-65.0) \\
5(31.3 \%) \\
\text { I (6.2\%) } \\
\text { I3 (86.7\%) } \\
\text { II (73.3\%) }\end{array}$ & $\begin{array}{l}3.1(2.9-3.8) \\
83.0(74.0-89.0) \\
2.2(2.1-2.6) \\
85.5(80.0-97.0) \\
71.5(67.0-76.0) \\
56.0(44.0-66.5) \\
6(27.3 \%) \\
1(4.5 \%) \\
19(95.0 \%) \\
13(65.0 \%)\end{array}$ & $\begin{array}{l}<0.001 \\
0.284 \\
<0.001 \\
<0.001 \\
<0.001 \\
<0.001 \\
<0.001 \\
<0.001 \\
<0.001 \\
<0.001\end{array}$ \\
\hline $\begin{array}{l}\text { Radiotherapy technique } \\
\text { 3DCRT/IMRT } \\
\text { SBRT }\end{array}$ & $\begin{array}{l}37(57.8 \%) \\
27(42.2 \%)\end{array}$ & $\begin{array}{l}85(64.4 \%) \\
47(35.6 \%)\end{array}$ & $\begin{array}{l}7(43.8 \%) \\
9(56.2 \%)\end{array}$ & $\begin{array}{l}14 \text { (63.6\%) } \\
8(36.4 \%)\end{array}$ & 0.395 \\
\hline $\begin{array}{l}\text { Radiotherapy planning } \\
\text { parameters for total lung volume } \\
\text { Mean dose (cGy) } \\
V_{5}(\%) \\
V_{20}(\%)\end{array}$ & $\begin{array}{l}836.0(544.4-1104.9) \\
27.0(20.9-36.5) \\
14.7(9.1-20.4)\end{array}$ & $\begin{array}{l}769.6(560.2-1052.3) \\
29.1(22.7-36.8) \\
13.6(9.5-18.5)\end{array}$ & $\begin{array}{l}632.6(498.3-1007.3) \\
27.2(19.3-33.3) \\
11.5(7.9-18.0)\end{array}$ & $\begin{array}{l}708.1(608.9-987.6) \\
27.9(25.1-33.2) \\
11.9(9.0-18.2)\end{array}$ & $\begin{array}{l}0.714 \\
0.822 \\
0.249\end{array}$ \\
\hline
\end{tabular}

Notes: Data are presented as number (\%) or median (interquartile range). *Non-COPD, non-CPFE, and non-IPF. ${ }^{\dagger}$ Pack-year was calculated among I85 current or exsmokers. ${ }^{\ddagger}$ DLco was available in 204 patients.

Abbreviations: 3DCRT, 3-dimensional conformal radiation therapy; COPD, chronic obstructive pulmonary disease; CPFE, combined pulmonary fibrosis and emphysema; ECOG, Eastern Cooperative Oncology Group; $\mathrm{DL}_{\mathrm{CO}}$, diffusing capacity of the lung for carbon monoxide; FEV , forced expiratory volume in I second; IMRT, intensity-modulated radiation therapy; IPF, idiopathic pulmonary fibrosis; NSCLC, non-small cell lung cancer; SBRT, stereotactic body radiation therapy; $V_{D}$, percentage volume of organ receiving $\geq$ D Gy.

\section{Survival Outcomes And Treatment-}

\section{Related Complications}

During the median 17 months of follow-up (range, 1-92 months), significantly different survivals according to underlying pulmonary diseases were observed in patients treated with definitive radiotherapy alone (Figure 1). The median survivals in the control, COPD, CPFE, and IPF groups were $32,49,17$, and 12 months, respectively 


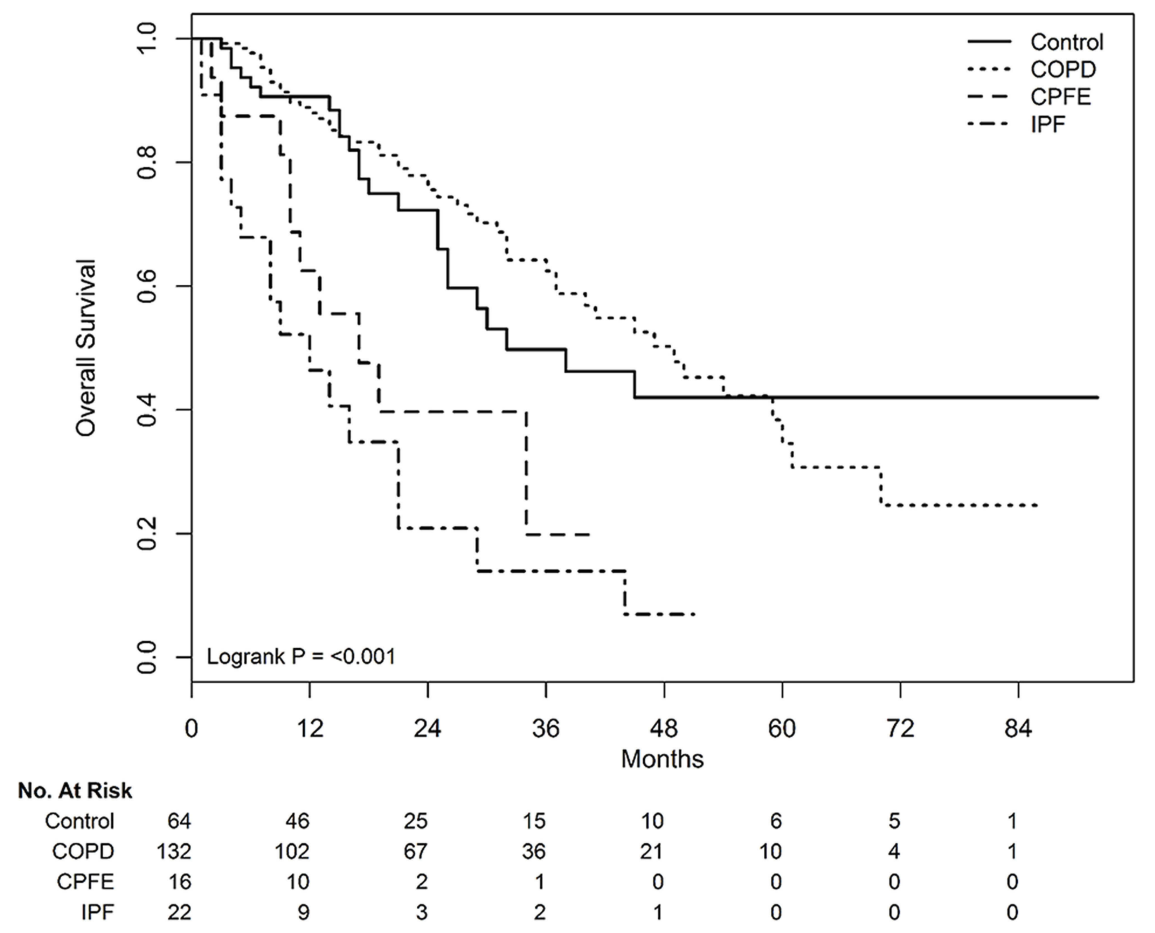

Figure I Overall survival curves according to underlying pulmonary diseases in patients treated with definitive radiotherapy alone.

$(P<0.001)$. In subgroup analysis according to clinical stages, survival rates were significantly different according to underlying pulmonary disease, in both stage I $(P<0.001$, Figure $2 \mathrm{~A})$ and II $(P<0.001$, Figure $2 \mathrm{~B})$ patients. After adjustment for confounding factors, coexisting COPD showed a similar OS as that of the control group. However, the presence of CPFE (adjusted HR, 3.034; 95\% CI, 1.328-6.931 in model 1 and adjusted HR, 3.382; 95\% CI, 1.472-7.769 in model 2)

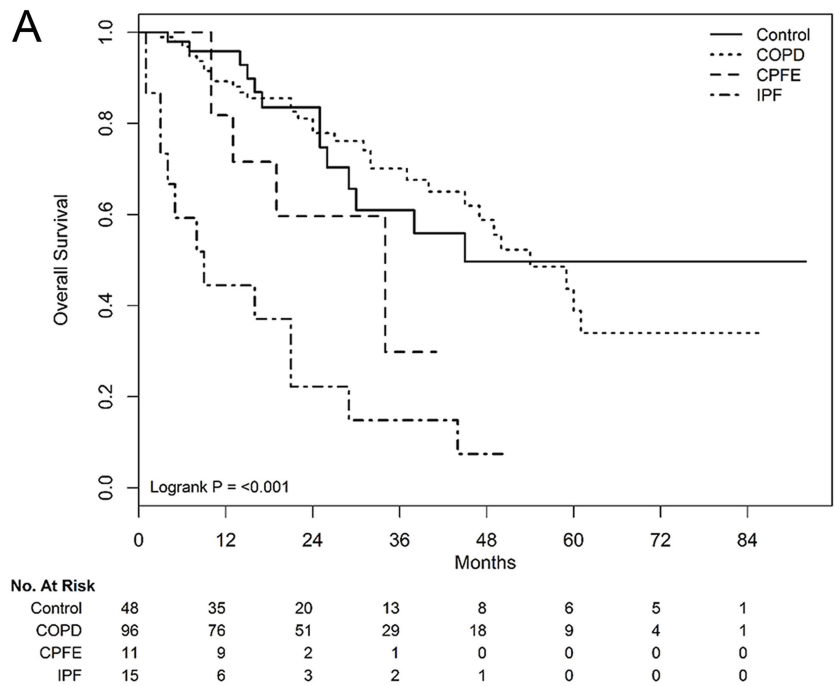

and IPF (adjusted HR, 4.246; 95\% CI, 2.06-8.753 in model 1 and adjusted HR, 4.061; 95\% CI, 1.963-8.403 in model 2) were associated with a poorer OS than that of the control group (Table 2). Treatment-related pulmonary toxicity is described in Table 3 . The incidence of grade $\geq 3 \mathrm{RP}$ in the control, COPD, CPFE, and IPF groups were 1.6\% (1/64), $2.3 \%(3 / 132), 6.3 \%(1 / 16)$, and 31.8\% (7/22), respectively $(P<0.001)$.

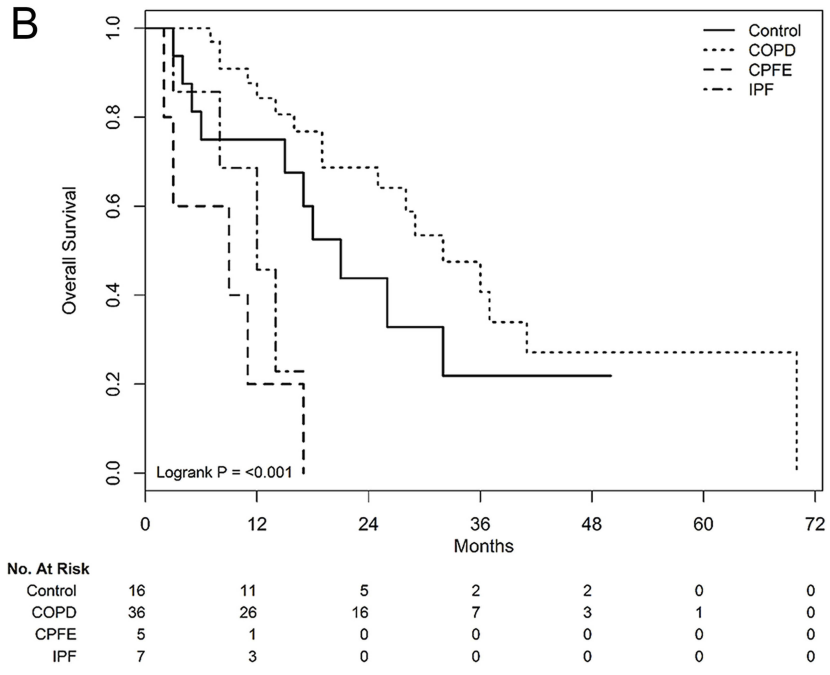

Figure 2 Overall survival curves according to underlying pulmonary diseases in subgroup analysis according to clinical stages; stage I (A) and II (B). 
Table 2 Cox Proportional Hazard Analysis For Factors Associated With Overall Survival $(\mathrm{N}=234)$

\begin{tabular}{|l|l|l|l|}
\hline Characteristics & Hazard Ratio & $\mathbf{9 5 \%} \mathbf{C I}$ & P Value \\
\hline Crude & & & \\
Control & Reference & & \\
COPD & 0.927 & $0.564-1.524$ & 0.765 \\
CPFE & 2.853 & $1.343-6.062$ & 0.006 \\
IPF & 4.344 & $2.301-8.201$ & $<0.001$ \\
\hline Model I & & & \\
Control & Reference & & \\
COPD & 1.326 & $0.725-2.425$ & 0.360 \\
CPFE & 3.034 & $1.328-6.931$ & 0.009 \\
IPF & 4.246 & $2.060-8.753$ & $<0.001$ \\
\hline Model 2 & & & \\
Control & Reference & & \\
COPD & 1.306 & $0.723-2.358$ & 0.376 \\
CPFE & 3.382 & $1.472-7.769$ & 0.004 \\
IPF & 4.061 & $1.963-8.403$ & $<0.001$ \\
\hline
\end{tabular}

Notes: Model I adjusted for age, smoking status, performance status (ECOG $\leq$ I or $\geq 2$ ), clinical stage (clinical stage I or II), $\mathrm{FEV}_{1} \leq 80 \%$ pred and DLco $\leq 60 \%$ pred. Model 2 adjusted for age, smoking status, performance status (ECOG $\leq 1$ or $\geq 2$ ), clinical stage (clinical stage I or II), $\mathrm{FEV}_{1} \leq 80 \%$ pred, DLco $\leq 60 \%$ pred and Radiotherapy technique.

Abbreviations: $\mathrm{Cl}$, confidence interval; COPD, chronic obstructive pulmonary disease; CPFE, combined pulmonary fibrosis and emphysema; IPF, idiopathic pulmonary fibrosis.

\section{Discussion}

Definitive radiotherapy can be an alternative treatment option for patients with medically inoperable early-stage NSCLC. However, the treatment outcome of definitive radiotherapy for patients with early-stage NSCLC and chronic pulmonary diseases such as COPD, CPFE, and IPF have not been fully elucidated. In this context, we evaluated the impact of co-existing COPD, IPF, and CPFE on overall survival following definitive radiotherapy in patients with medically inoperable stage I-II NSCLC. The results of this current study demonstrated that underlying COPD was not associated with the outcome of definitive radiotherapy, while the presence of IPF and CPFE resulted in poorer survivals than those of patients without underlying pulmonary disease such as COPD, CPFE, and IPF.

In patients who were not feasible for surgical resection thus underwent definitive radiotherapy for early-stage NSCLC, we observed that patients with COPD showed similar OS to the control patients without underlying pulmonary disease such as COPD, CPFE, and IPF. The development of Grade $\geq 3$ RP was also similar between COPD patients and control patients with lung cancer. Given that control patients did not have underlying pulmonary diseases but were unable to undergo surgical resection for multiple reasons such as old age, poor performance status, or co-morbidities, ${ }^{1}$ our study showed that the presence of COPD itself did not increase the risk of overall mortality, contrary to the presence of CPFE or IPF.

IPF is another pulmonary disease well known for its association with lung cancer and poor prognosis. ${ }^{15,25}$ Previous studies on the surgical treatment of early-stage lung cancer have shown that the co-existence of IPF resulted in 5- to 14-fold increase in mortality compared to that in patients without IPF. ${ }^{13,14,26}$ Furthermore, treatment-related complications substantially contributed to the poor prognosis of those patients. ${ }^{13,14,26}$ Therefore, in an effort to decrease the side effects of treatment and as an alternative therapy for patients who cannot tolerate surgical resection, radiotherapy has been considered as a definitive treatment for patients with early-stage NSCLC and IPF. However, the survival outcomes of definitive radiotherapy have not been fully elucidated. Although containing relatively few patients, our study showed that the presence of IPF has a detrimental effect on the survival of patients with early-stage NSCLC. In addition, $31.8 \%$ of patients with IPF developed Grade $\geq 3 \mathrm{RP}$, which was significantly higher than those with COPD or CPFE.

Table 3 Radiation Pneumonitis According To Underlying Pulmonary Diseases ( $N=234)$

\begin{tabular}{|l|l|l|l|l|l|}
\hline Characteristics & Control* & COPD & CPFE & IPF & P value \\
\hline All patients (N=234) & 64 & 132 & 16 & 22 & $7(31.8 \%)$ \\
$\geq$ Grade 3 RP & $\mathrm{I}(\mathrm{I} .6 \%)$ & $3(2.3 \%)$ & $\mathrm{I}(6.3 \%)$ & $<0.00 \mathrm{I}$ \\
Subgroup analysis with stage I NSCLC (N=I70) & 48 & 96 & $\mathrm{II}$ & 15 & $4(26.7 \%)$ \\
$\geq$ Grade 3 RP & $0(0.0 \%)$ & $2(2.1 \%)$ & $\mathrm{I}(9.1 \%)$ & 7 & \\
Subgroup analysis with stage II NSCLC (N=64) & 16 & 36 & 5 & $0.00 \mathrm{I}$ \\
$\geq$ Grade 3 RP & $\mathrm{I}(6.3 \%)$ & $\mathrm{I}(2.8 \%)$ & $0(0.0 \%)$ & $3(42.9 \%)$ & 0.003 \\
\hline
\end{tabular}

Notes: Data are presented as $\mathrm{n}$ or number (\%). *Non-COPD, non-CPFE, and non-IPF.

Abbreviations: COPD, chronic obstructive pulmonary disease; CPFE, combined pulmonary fibrosis and emphysema; IPF, idiopathic pulmonary fibrosis; RP, radiation pneumonitis. 
Further studies are required to determine an optimal treatment modality and criteria for patient selection.

There is an increasing recognition of the relationship between lung cancer and CPFE, a unique disease entity encompassing the features of both IPF and emphysema. CPFE in lung cancer is not only associated with an increased risk of lung cancer development but is also a factor affecting the poor prognosis. ${ }^{27,28}$ Usui et $\mathrm{al}^{17}$ reported a poorer prognosis with a median survival of 10.8 months in patients with CPFE and lung cancer compared to patients with either fibrosis or emphysema alone. Of note, 20 of 101 (19.8\%) patients with CPFE and lung cancer developed acute lung injury during treatment, indicating that treatment-related toxicities may be one reasons for the grave outcomes. In particular, the incidence of acute lung injury following radiotherapy was $16.7 \%$ (1/6), while the incidences following surgery and chemotherapy were $27.3 \%$ (9/33) and 20\% (12/60), respectively. Several studies have evaluated the outcomes of surgical resection for patients with early-stage NSCLC and CPFE. The results on survival and postoperative complication were not promising, comparable to or poorer than those of patients with IPF. $^{29,30}$ Frequent postoperative complications were one of the factors associated with a poor prognosis. Yet, data are scarce regarding treatment outcomes and treatment-related complications following radiotherapy in those patients. Our study showed that patients with CPFE showed a slightly better prognosis than IPF, which may give insight into the characteristics of these patients. However, larger studies are necessary to fully understand the characteristics and outcomes of these patients.

With rapid advancement in immune-oncology, immune checkpoint inhibitors (ICIs) have shown promising results and are now considered as standard of care in advanced NSCLC. ${ }^{31,32}$ In particular, the presence of COPD is associated with better survival outcomes in patients with advanced NSCLC treated with ICIs. ${ }^{33}$ Of note, recent studies demonstrated that combining immunotherapy and radiotherapy may improve the outcome of oligometastatic or advanced lung cancer with tolerable side effects. ${ }^{34,35}$ In this light, further studies are warranted to determine the possible role of immunotherapy in treatment of early NSCLC with underlying pulmonary diseases receiving radiotherapy. Another area of particular interest in the field of radiotherapy is image-guided radiotherapy. ${ }^{36,37}$ Considering its greater capacity of sparing functioning lung tissues or less-irritating sensitive lung tissue compared to conventional radiotherapy technique, image- guided radiotherapy may be a potential option for patients with NSCLC with pulmonary diseases. Prospective studies are required to evaluate its efficacy and safety.

To fully understand the results of our study, several limitations must be acknowledged. First, although our data were collected from all consecutive patients prospectively included in the radiotherapy registry of our center, its retrospective design indicates that there is always the possibility of selection bias. Furthermore, our study was conducted at a university-affiliated hospital with comprehensive cancer center with a specialized interstitial lung disease clinic, which may limit the generalizability of our findings to other centers. Second, histological confirmation of cancer was not possible for some patients due to a high risk of complications following the biopsy. Nevertheless, vigorous investigations including serial chest CT evaluation and PET CT review were performed before making a diagnosis of lung cancer. Finally, COPD was defined based on pre-bronchodilator pulmonary function tests. Thus, some of the patients may have been misclassified. However, as post-bronchodilator pulmonary function tests are not routinely performed in patients who receive radiotherapy, our data may be more informative in a realworld clinical setting.

\section{Conclusion}

Patients with underlying COPD tolerated radiation treatment compared to the control patients. However, IPF and CPFE were associated with fatal survival outcomes. Further study should focus on identifying clinical subgroups among patients with IPF that will benefit from definitive radiotherapy.

\section{Abbreviations}

3DCRT, 3-dimensional conformal RT; $\mathrm{BED}_{10}$, biologically equivalent doses at $\alpha / \beta$ of $10 \mathrm{~Gy}$; $\mathrm{CI}$, confidence interval; COPD, chronic obstructive pulmonary disease; CPFE, combined pulmonary fibrosis and emphysema; CTV, clinical target volume; $\mathrm{DL}_{\mathrm{CO}}$, diffusing capacity of the lung for carbon monoxide; EBUS-TBNA, endobronchial ultrasound-guided transbronchial needle aspiration; $\mathrm{FEV}_{1}$, forced expiratory volume in one second; FVC, forced vital capacity; GOLD, Global Initiative for Chronic Obstructive Lung Disease; GTV, gross tumor volume; HRCT, high-resolution CT; HR, hazard ratio; IMRT, intensity-modulated RT; IPF, idiopathic pulmonary fibrosis; NSCLC, non-small cell lung cancer; OS, overall survival; PET-CT, 18F-fluorodeoxyglucose positron emission tomography with CT; PTV, planning target volume; SBRT, stereotactic body radiation therapy. 


\section{Ethics Approval And Consent To Participate}

This study was approved by the ethics committee of Samsung Medical Center (no. 2018-08-108) and informed consent was waived due to the retrospective nature.

\section{Availability Of Data And Material}

The datasets used and/or analyzed during the current study are available from the corresponding author on reasonable request.

\section{Acknowledgments}

This work was supported by the National Research Foundation of Korea (NRF), grant funded by the Ministry of Science and ICT (NRF-2017M2A2A7A02018569).

\section{Disclosure}

The authors report no conflicts of interest in this work.

\section{References}

1. Donington J, Ferguson M, Mazzone P, et al. American College of Chest Physicians and Society of Thoracic Surgeons consensus statement for evaluation and management for high-risk patients with stage I non-small cell lung cancer. Chest. 2012;142(6):1620-1635. doi:10.1378/chest.12-0790

2. Zhai R, Yu X, Shafer A, Wain JC, Christiani DC. The impact of coexisting COPD on survival of patients with early-stage non-small cell lung cancer undergoing surgical resection. Chest. 2014;145(2):346-353. doi:10.1378/ chest.13-1176

3. Yoshida Y, Kage H, Murakawa T, et al. Worse prognosis for stage IA lung cancer patients with smoking history and more severe chronic obstructive pulmonary disease. Ann Thorac Cardiovasc Surg. 2015;21(3):194-200. doi:10.5761/atcs.oa.14-00200

4. Saito Y, Kawai Y, Takahashi N, et al. Survival after surgery for pathologic stage IA non-small cell lung cancer associated with idiopathic pulmonary fibrosis. Ann Thorac Surg. 2011;92(5):1812-1817. doi:10.1016/j.athoracsur.2011.06.055

5. Ettinger DS, Aisner DL, Wood DE, et al. NCCN guidelines insights: non-small cell lung cancer, version 5.2018. J Natl Compr Canc Netw. 2018;16(7):807-821. doi:10.6004/jncen.2018.0062

6. Sin DD, Man SF. Chronic obstructive pulmonary disease as a risk factor for cardiovascular morbidity and mortality. Proc Am Thorac Soc. 2005;2(1):8-11. doi:10.1513/pats.200404-032MS

7. Moro-Sibilot D, Aubert A, Diab S, et al. Comorbidities and Charlson score in resected stage I nonsmall cell lung cancer. Eur Respir J. 2005;26 (3):480-486. doi:10.1183/09031936.05.00146004

8. Rancati T, Ceresoli GL, Gagliardi G, Schipani S, Cattaneo GM. Factors predicting radiation pneumonitis in lung cancer patients: a retrospective study. Radiother Oncol. 2003;67(3):275-283. doi:10.1016/s0167-8140 (03)00119-1

9. Takeda A, Kunieda E, Ohashi T, et al. Severe COPD is correlated with mild radiation pneumonitis following stereotactic body radiotherapy. Chest. 2012;141(4):858-866. doi:10.1378/chest.11-1193

10. Zhou Z, Song X, Wu A, et al. Pulmonary emphysema is a risk factor for radiation pneumonitis in NSCLC patients with squamous cell carcinoma after thoracic radiation therapy. Sci Rep. 2017;7(1):2748. doi:10.1038/ s41598-017-02739-4

11. King TE Jr., Pardo A, Selman M. Idiopathic pulmonary fibrosis. Lancet. 2011;378(9807):1949-1961. doi:10.1016/S0140-6736(11)60052-4
12. Fujimoto T, Okazaki T, Matsukura T, et al. Operation for lung cancer in patients with idiopathic pulmonary fibrosis: surgical contraindication? Ann Thorac Surg. 2003;76(5):1674-1678; discussion 1679. doi:10.1016/s0003-4975(03)00966-4

13. Kumar P, Goldstraw P, Yamada K, et al. Pulmonary fibrosis and lung cancer: risk and benefit analysis of pulmonary resection. $J$ Thorac Cardiovasc Surg. 2003;125(6):1321-1327. doi:10.1016/s0022-5223(03) 00028-x

14. Kushibe K, Kawaguchi T, Takahama M, Kimura M, Tojo T, Taniguchi S. Operative indications for lung cancer with idiopathic pulmonary fibrosis. Thorac Cardiovasc Surg. 2007;55(8):505-508. doi:10.1055/s-2007965645

15. Tomassetti S, Gurioli C, Ryu JH, et al. The impact of lung cancer on survival of idiopathic pulmonary fibrosis. Chest. 2015;147(1):157-164. doi:10.1378/chest.14-0359

16. Jankowich MD, Rounds SIS. Combined pulmonary fibrosis and emphysema syndrome: a review. Chest. 2012;141(1):222-231. doi:10.1378/ chest.11-1062

17. Usui K, Tanai C, Tanaka Y, Noda H, Ishihara T. The prevalence of pulmonary fibrosis combined with emphysema in patients with lung cancer. Respirology. 2011;16(2):326-331. doi:10.1111/j.14401843.2010.01907.x

18. Miller MR, Hankinson J, Brusasco V, et al. Standardisation of spirometry. Eur Respir J. 2005;26(2):319-338. doi:10.1183/09031936. 05.00034805

19. American Thoracic Society. Single-breath carbon monoxide diffusing capacity (transfer factor). Recommendations for a standard technique1995 update. Am J Respir Crit Care Med. 1995;152(6 Pt 1):2185-2198. doi:10.1164/ajrccm.152.6.8520796

20. Choi JK, Paek D, Lee JO. Normal Predictive Values of Spirometry in Korean Population. Tuberc Respir Dis. 2005;58(3):230-242.

21. Harvey BG, Strulovici-Barel Y, Kaner RJ, et al. Risk of COPD with obstruction in active smokers with normal spirometry and reduced diffusion capacity. Eur Respir J. 2015;46(6):1589-1597. doi:10.1183/ 13993003.02377-2014

22. Raghu G, Collard HR, Egan JJ, et al. An official ATS/ERS/JRS/ ALAT statement: idiopathic pulmonary fibrosis: evidence-based guidelines for diagnosis and management. Am J Respir Crit Care Med. 2011;183(6):788-824. doi:10.1164/rccm.2009-040GL

23. Cottin V, Nunes H, Brillet PY, et al. Combined pulmonary fibrosis and emphysema: a distinct underrecognised entity. Eur Respir J. 2005;26 (4):586-593. doi:10.1183/09031936.05.00021005

24. Goldstraw P, Crowley J, Chansky K, et al. The IASLC lung cancer staging project: proposals for the revision of the TNM stage groupings in the forthcoming (seventh) edition of the TNM classification of malignant tumours. J Thorac Oncol. 2007;2(8):706-714. doi:10.1097/JTO.0b0 $13 \mathrm{e} 31812 \mathrm{f3cla}$

25. Matsushita H, Tanaka S, Saiki Y, et al. Lung cancer associated with usual interstitial pneumonia. Pathol Int. 1995;45(12):925-932. doi:10.1111/ j.1440-1827.1995.tb03417.x

26. Watanabe A, Higami T, Ohori S, Koyanagi T, Nakashima S, Mawatari T. Is lung cancer resection indicated in patients with idiopathic pulmonary fibrosis? J Thorac Cardiovasc Surg. 2008;136(5):1357-1363, 1363 e1351-1352. doi:10.1016/j.jtcvs.2008.07.016

27. Kwak N, Park CM, Lee J, et al. Lung cancer risk among patients with combined pulmonary fibrosis and emphysema. Respir Med. 2014;108 (3):524-530. doi:10.1016/j.rmed.2013.11.013

28. Kitaguchi Y, Fujimoto K, Hanaoka M, Kawakami S, Honda T, Kubo K. Clinical characteristics of combined pulmonary fibrosis and emphysema. Respirology. 2010;15(2):265-271. doi:10.1111/j.14401843.2009.01676.x

29. Otsuka H, Sugino K, Hata Y, et al. Clinical features and outcomes of patients with lung cancer as well as combined pulmonary fibrosis and emphysema. Mol Clin Oncol. 2016;5(3):273-278. doi:10.3892/ mco.2016.954 
30. Fukui M, Suzuki K, Matsunaga T, Oh S, Takamochi K. Outcomes of lung cancer resection for patients with combined pulmonary fibrosis and emphysema. Surg Today. 2016;46(3):341-347. doi:10.1007/ s00595-015-1234-z

31. Antonia SJ, Villegas A, Daniel D, et al. Durvalumab after chemoradiotherapy in stage III non-small-cell lung cancer. $N$ Engl J Med. 2017;377(20):1919-1929. doi:10.1056/NEJMoa1709937

32. Reck M, Rodriguez-Abreu D, Robinson AG, et al. Pembrolizumab versus chemotherapy for PD-L1-positive non-small-cell lung cancer. $N$ Engl J Med. 2016;375(19):1823-1833. doi:10.1056/NEJMoa1606774

33. Shin SH, Park HY, Im Y, et al. Improved treatment outcome of pembrolizumab in patients with nonsmall cell lung cancer and chronic obstructive pulmonary disease. Int $J$ Cancer. 2019. doi:10.1002/ijc.32235

34. Bauml JM, Mick R, Ciunci C, et al. Pembrolizumab after completion of locally ablative therapy for oligometastatic non-small cell lung cancer: a phase 2 trial. JAMA Oncol. 2019;5:1283. doi:10.1001/ jamaoncol.2019.1449
35. Theelen W, Peulen HMU, Lalezari F, et al. Effect of pembrolizumab after stereotactic body radiotherapy vs pembrolizumab alone on tumor response in patients with advanced non-small cell lung cancer: results of the PEMBRO-RT Phase 2 randomized clinical trial. JAMA Oncol. 2019;5:1276. doi:10.1001/ jamaoncol.2019.1478

36. Kasmann L, Niyazi M, Blanck O, et al. Predictive and prognostic value of tumor volume and its changes during radical radiotherapy of stage III non-small cell lung cancer: a systematic review. Strahlenther Onkol. 2018;194(2):79-90. doi:10.1007/s00066-0171221-y

37. Elsayad K, Samhouri L, Scobioala S, Haverkamp U, Eich HT. Is tumor volume reduction during radiotherapy prognostic relevant in patients with stage III non-small cell lung cancer? J Cancer Res Clin Oncol. 2018;144(6):1165-1171. doi:10.1007/s00432-0182640-6

\section{Publish your work in this journal}

The International Journal of COPD is an international, peer-reviewed journal of therapeutics and pharmacology focusing on concise rapid reporting of clinical studies and reviews in COPD. Special focus is given to the pathophysiological processes underlying the disease, intervention programs, patient focused education, and self management protocols. This journal is indexed on PubMed Central, MedLine and CAS. The manuscript management system is completely online and includes a very quick and fair peer-review system, which is all easy to use. Visit http://www.dovepress.com/testimonials.php to read real quotes from published authors. 